\title{
A materialidade significante da língua segundo Saussure: do som ao signo
}

The signifier materiality of language according to Saussure: from sound to sign

Mestranda CNPq em Estudos da Linguagem pelo Programa de Pós-Graduação em Letras da Universidade Federal do Rio Grande do Sul (UFRGS).

E-mail: larissa.hainzenreder@gmail.com
Larissa Schmitz Hainzenreder ${ }^{*}$

RESUMO: Este trabalho busca provocar uma discussão acerca da importância do aspecto fônico para os estudos saussurianos de modo a oferecer um olhar teórico-metodológico que ceda à materialidade significante o centro da reflexão linguística. Imagem acústica, figura vocal ou, finalmente, forma: Saussure parece encontrar em toda a tentativa de definir o significante a própria definição de língua. Acredita-se, assim, que a natureza do significante é o que coloca a língua à parte entre os sistemas semiológicos, estando no embrião da constituição do sujeito falante.

Palavras-chave: Som; Signo; Significante; Língua.

ABSTRACT: This paper aims at provoking a discussion about the importance of the phonic aspect for the Saussurian theory in order to provide a theoretical and methodological approach that places the signifier materiality in the center of Saussure's linguistic theory. Acoustic image, vocal figure or ultimately form: in every attempt to define the signifier Saussure seems to find the definition of language itself. We believe therefore that the nature of the signifier is what places the language apart from others semiotic systems, being the "embryo" of the constitution of the speaking subject. KEYworDS: Sound; Sign; Signifier; Language. 


\section{Considerações iniciais}

A contribuição capital de Ferdinand de Saussure para os estudos da linguagem é inquestionável. Desde a publicação do póstumo Curso de linguística geral (CLG), foram muitos os desdobramentos que conceberam, do casamento com mentes fabulosas, perspectivas teórico-metodológicas que mudariam o rumo da linguística do século XX. Como uma extensão aos estudos saussurianos, nasceram diferentes formas de olhar para a linguagem. Estas, ainda que por vezes discordantes, não escondem nítida filiação ao mestre genebrino. A dívida é imensa. Saussure cobriu com seu manto todas as áreas que compreendem a linguística como a temos hoje, e é sob uma delas em particular que procuro abrigo às linhas que se seguem - a fonologia. É a ela que o CLG reserva seu único apêndice isolado do restante dos capítulos, além de um capítulo introdutório, e pergunto-me bem o porquê. $\mathrm{O}$ que a fonologia tem de especial? Antes de esboçar qualquer raciocínio que possa satisfazer a essa questão, é necessário compreender o que Saussure entende por fonologia:

FONOLOGIA (ou estudo da fonação) - Estudo que, receba o nome que for, é absolutamente independente e distinto, não apenas da fonética das diferentes línguas mas, em geral, da linguística. Ela constitui, todavia, uma ciência auxiliar muito importante para a linguística. - E isso devido unicamente ao recorte fonético (SAUSSURE, 2004, p. 75, grifos do autor).

Para Saussure, a fonologia é, então, uma ciência auxiliar responsável pelo estudo da fonação, a qual, de acordo com o mestre, não diz respeito à linguística e nem à fonética. Ao que, então, estão associadas as espécies fonológicas? É Saussure (1995, p. 43) mesmo quem esclarece: "a Fonologia [...] só se refere à fala”. Ao contrário do que se acredita, essa afirmação de Saussure recobra muita atenção ao que, infelizmente, pouco se atendeu durante o percurso científico da linguística moderna.

Em primeiro lugar, a questão que Saussure formula ao colocar-se diante do problema da linguagem diz respeito à necessidade de definição de um campo próprio para estudá-la em relação às ciências humanas. 0 fundamento da linguística enquanto ciência veio a reclamar, durante toda a obra saussuriana, a especificação de um objeto central que se revelou em todo singular: a língua, dirá Saussure (1995, p. 22), “é um objeto bem definido no conjunto heteróclito dos fatos de linguagem", podendo ser localizada "na porção determinada do circuito [da fala] em que uma imagem auditiva vem associar-se a um conceito" ${ }^{1}$, e acrescenta: "a língua, assim delimitada no conjunto dos fatos de linguagem, é classificável entre os fatos humanos" (1995, p. 23).

Ao conceder à língua um princípio de classificação, Saussure (1995, p. 24, grifos do autor) faz "intervir uma nova ordem de fatos" e elabora, então, princípios para uma semiologia geral: "Pode-se, então, conceber uma ciência que estude a vida dos signos no seio da vida social; [...] chamá-la-emos de Semiologia [...]. Ela nos ensinará em que consistem os signos, que leis os regem", estando sua relação com a linguística definida pelo seguinte: "A Linguística não é senão uma parte dessa ciência geral; as leis que a Semiologia descobrir serão aplicáveis à Linguística e esta se achará dessarte vinculada a um domínio bem definido no conjunto dos fatos humanos". Saussure parece hierarquizar a semiologia como uma ciência de maior abrangência do que a linguística que lhe é integrante, porém, uma leitura atenta desse momento da reflexão saussuriana mostra a "invenção" da semiologia de algum modo escrita na história da linguística:

${ }_{1}^{1}$ Sobre o circuito da fala, ver SAUSSURE, 1995, p. 19. 
Por que não é esta [a semiologia] ainda reconhecida como ciência autônoma, tendo, como qualquer outra, seu próprio objeto? É que rodamos em círculo; dum lado, nada mais adequado que a língua para fazer-nos compreender a natureza do problema semiológico; mas para formulá-lo convenientemente, necessário se faz estudar a língua em si [...] (SAUSSURE, 1995, p. 24).

Está fundado o paradoxo: a natureza da língua é a condição insuperável para solucionar o problema da semiologia, isto é, do signo no seio da vida social; contudo, é também o único modo de criá-lo adequadamente. Somos levados a concluir que antes da língua não há sequer significação e, se a língua é o objeto central da linguística, logo, na perspectiva de Saussure, não há possibilidade da semiologia antes da linguística. Aqui, o paradoxo se estende: foi preciso definir a linguística para criar a semiologia, e é preciso a semiologia para compreender a linguística na sua essência. Era isso o que faltava aos olhos de Saussure (1995, p. 25): "estudar a língua em si", e não "em função de outra coisa, sob outros pontos de vista".

Mas o que significa estudar a língua em si? Em primeiro lugar, esquecer a "concepção superficial do grande público" que "vê na língua apenas uma nomenclatura"; em segundo lugar, abstrair-se do "ponto de vista do psicólogo", que considera o "mecanismo do signo no indivíduo" e não atinge a sua natureza social; em terceiro lugar, adotar uma abordagem que estude $o$ signo socialmente atentando às "características que pertencem somente aos sistemas semiológicos em geral e à língua em particular", dispensando "os caracteres da língua que a vinculam às outras instituições" (SAUSSURE, 1995, p. 25). Por esse ângulo, ser linguístico é ser semiológico. É porque Saussure eleva o problema linguístico a um problema semiológico que pode afirmar algo sobre a verdadeira natureza da língua. Sem dúvida, a proposição mais importante da tese saussuriana sobre o signo reside em constatar que "é próprio da língua, como de todo sistema semiológico, não admitir nenhuma diferença entre o que distingue uma coisa e o que a constitui" (SAUSSURE, 2004, p. 224, grifo do autor). Com isso, define-se o signo, o qual serve de base para o sistema linguístico e, ao mesmo tempo, para o sistema semiológico: ser diferencial e, por conseguinte, constituir valor.

A língua, então, fica assim definida como um sistema de signos que constitui a parte social da linguagem. Porém, conceber à língua uma definição não recapitula seus caracteres particulares. Para caracterizá-la nesses termos é necessário abstraí-la da heterogeneidade da qual faz parte para só então encontrar a sua natureza homogênea e compreender a sua essência singular. Saussure (1995, p. 23, grifo meu) assegura que a ciência da língua não apenas pode "prescindir de outros elementos da linguagem como só se torna possível quando tais elementos não estão misturados" - os "outros elementos da linguagem" aos quais se refere Saussure não remetem a outra coisa que não à fala, isto é, à fonação da língua.

Isso posto, temos que a linguística de Saussure é uma proposta epistemológica que busca dar conta do estudo científico da língua para dar a conhecer ao linguista a complexidade de sua tarefa diante de parte do problema da linguagem. Em última análise, a questão de Saussure consiste em definir os fundamentos primeiros e últimos de uma ciência da língua, de modo a delimitar para a linguística um objeto particular e os pontos de vista que lhe servem à analise. Para fazê-lo, no entanto, Saussure exclui de sua metodologia - e não de sua teoria - tudo o que não diz respeito à noção mesma de sistema, uma vez que a língua é assim definida. É apenas nesse sentido que a separação entre língua e fala desempenha um papel na linguística saussuriana.

Em segundo lugar, essa separação é, como dito, de caráter unicamente metodológico. Nenhuma epistemologia da linguística seria possível sem a noção mesma de fala, a qual está intrinsicamente relacionada à língua em todos os sentidos: 
a língua é necessária para que a fala seja inteligível e produza todos os seus efeitos; mas esta é necessária para que a língua se estabeleça; historicamente, o fato da fala vem sempre antes. Como se imaginaria associar uma ideia a uma imagem verbal se não se surpreendesse de início esta associação num ato de fala? [...] Enfim, é a fala que faz evoluir a língua: são as impressões recebidas ao ouvir os outros que modificam nossos hábitos linguísticos. Existe, pois, interdependência da língua e da fala; aquela é ao mesmo tempo o instrumento e o produto desta. Tudo isso, porém, não impede que sejam duas coisas absolutamente distintas (SAUSSURE, 1995, p. 27).

Dessa maneira, a relação entre língua e fala é clara: uma refere-se ao sistema e a outra aos fenômenos diacrônicos que o estabelecem. A separação que Saussure faz entre as duas noções refere-se a dois pontos de vista distintos, isto é, língua e fala são, para Saussure, dois meios diferentes de abordar a linguagem. Mas um objeto só pode ser definido em relação a outro, de modo que, para desenvolver uma ciência da língua, isto é, para situá-la nos fatos de linguagem, é necessário definir também a sua contraparte, a fala.

Não é por acaso que os editores do CLG reservam ao estudo da fonação um apêndice no livro que organizam sobre o curso ministrado por Saussure: ao referir-se somente à fala, a fonologia, é certo, não tem serventia à compreensão do funcionamento significante da língua enquanto sistema, a fisiologia do som em nada interfere no mecanismo linguístico; contudo, conforme nos é mostrado que Saussure enfatiza nas suas aulas, a fonologia faz-se uma disciplina auxiliar muito importante para a linguística, principalmente porque é da produção sonora - e isso inclui também a articulação dos sons - que demanda a percepção da imagem acústica que resultará no recorte da unidade.

Antes do recorte fonético, a língua não passa de uma massa amorfa de sons. Isso nos permite concluir que a fonologia é, literalmente, um apêndice do sistema linguístico. Essa conclusão, aparentemente simples, revela um aspecto da língua do qual o CLG não se propõe a tratar em pormenores, mas que, por alguma razão da qual desconheceremos a exatidão, seus editores não puderam negligenciar plenamente: $\mathrm{o}$ aspecto fônico. Finalmente tocamos a grande questão deste texto: a indiscutível separação metodológica entre língua e fala presente no CLG sonega o estatuto teórico do som na teoria saussuriana. Uma leitura estruturalista encobriu o falante, e o que ele faz com a língua, dos fundamentos da ciência da linguística.

Conforme explicitado, reconhecer à fala o aspecto fônico não é problema; o recalque recaiu, pois, em excluir, em certa medida, a produção sonora da concepção mesma de língua. O som, dirá Saussure (cf. 2004, p. 193) mais tarde, é constitutivo da significação.

A fonologia é importante para Saussure, porque estuda parte da materialização do significante, e o significante é importante para o sistema. Dizer que as espécies fonológicas se referem à fala é colocá-las frente a frente com a língua, o que em nada impede o exame separado de ambas as partes, mas evidencia de saída que algo da produção do som interessa à língua. Dessa maneira, o objetivo deste texto é discutir o que o som pode nos dizer sobre a língua.

A sonegação do aspecto fônico na constituição saussuriana de língua entrou pela porta do estruturalismo e impediu, de certa maneira, a entrada do sujeito falante para a teoria. Em vista disso, proponho uma releitura do CLG à luz da publicação posterior dos manuscritos saussurianos originais, no volume Escritos de Linguística Geral (ELG), em busca do estatuto teórico do som na teoria de Saussure outrora silenciado pela leitura estruturalista que se fez de sua obra. Creio, com isso, ser possível indicar na reflexão saussuriana acerca do som relação direta com a noção do valor linguístico, cuja afinidade com a questão do sentido pode viabilizar também a demarcação de um lugar para a constituição do sujeito falante na ciência da língua. 
A fim de oferecer uma solução mais ou menos satisfatória às hipóteses levantadas, o caminho a ser percorrido neste texto partirá da distinção saussuriana entre a noção de som apenas como figura vocal e a noção de som como signo, tocando na relação entre as duas maneiras de se conceber o fônico. Conforme será visto, esse percurso levará ao encontro da integração forma-sentido, refletindo sobre o mecanismo mesmo da língua e ensinando algo sobre a sua definição.

\section{A figura vocal como tal}

Em termos de língua, uma figura vocal por si só nada significa (cf. SAUSSURE, 2004, p. 68). Em outras palavras: é possível resgatar-lhe a porção sonora que representa, mas não se pode fazer o mesmo quanto ao seu estatuto linguístico; este está em absoluta dependência com outros termos do sistema. Isso significa que a língua não pode ser reduzida ao som; a imagem acústica que se reconhece quando alguém fala não pode ser jamais confundida com o som em si, simplesmente porque este é unicamente físico enquanto que aquela é também psíquica. Todavia, não é correto assumir que o som, enquanto tal, não desempenha um papel na comunicação linguística.

O circuito da fala, de acordo com Saussure (1995, p. 20), contém uma parte exterior que representa a "vibração dos sons indo da boca ao ouvido" e que é também a parte não-psíquica do circuito por incluir "os fatos fisiológicos" e "os fatos físicos". A divisão proposta por Saussure para abordar o circuito encontra apoio no fato de que é impossível "separar o som da articulação vocal" na mesma medida em que qualquer definição do "movimento dos órgãos vocais" é imprecisa, uma vez que "se fizer abstração da impressão acústica" (SAUSSURE, 1995, p. 16).

Isso posto, tem-se, na reflexão do estatuto do som em Saussure, uma diferença fundamental entre a imagem acústica propriamente dita e o som que ela imprime. Mais do que isso, sem essa compreensão, não é possível se aproximar da definição saussuriana de língua como um sistema de valores, conforme explica Saussure (1995, p. 49): “Não somente a impressão produzida no ouvido nos é dada tão diretamente quanto a imagem motriz dos órgãos, como também é ela a base de toda teoria". Assim, tem-se, de um lado, o som material, que é puramente físico e, de outro, a impressão psíquica desse som, finalmente definida por Saussure (1995, p. 80) como a "representação que dele nos dá o testemunho de nossos sentidos". Dessa maneira, é da abstração da associação de uma ideia à forma sonora que resulta uma figura vocal, ou seja, sem uma significação tem-se apenas puro som. Por essa razão, Saussure (1995, p. 212) faz mais do que afirmar a impossibilidade de o som, por si só, dar conta da identidade linguística.

Quanto à noção de identidade, Saussure $(2004$, p. 86) define o som enquanto figura vocal como o resultado da abstração "de todo fragmento de sentido" e se pergunta se o som, nessa condição, pode manifestar algum valor. Evidentemente que não, isso porque o valor de uma figura vocal depende de sua relação no sistema linguístico com outros termos de mesma ordem, e, para que seja permitida a entrada de uma figura vocal no sistema, é necessária sua integração com um sentido de onde depende o seu status semiológico, isto é, a sua significância. Uma vez destituído de sentido, o som não pertence a uma língua sequer:

Todo o estudo de uma língua como sistema, ou seja, de uma morfologia se resume, como se preferir, no estudo do emprego das formas, ou no da representação das ideias. 0 errado é pensar que há, em algum lugar, formas (que existem por si mesmas, fora de seu emprego) ou, em algum lugar, ideias (que existem por si mesmas, fora de sua representação) (SAUSSURE, 2004, p. 32, grifos do autor).

A figura vocal, nesse sentido, é uma forma abstraída de seu emprego linguístico, ou seja, o som na condição de figura vocal pertence ao domínio 
da fisiologia e da acústica apenas - nada pode dizer sobre a língua. É a essa condição do som como concretude que Saussure se refere quando afirma ser impossível "que o som, elemento material, pertença por si à língua" não sendo mais do que uma substância que ela "põe em jogo" (1995, p. 137) - na língua em si não há nada de substancial.

Ainda que seja necessário repetir, por todos os cantos que a linguística alcança, que o som como figura vocal em nada diz respeito à língua, isso não significa que esteja fora da linguagem. De acordo com Saussure (2004, p. 24), e isso é muito importante, a linguagem é dividida por um "dualismo profundo", que, ao contrário do que se pensa, "não reside no dualismo do som e da ideia, do fenômeno vocal e do fenômeno mental", mas:

na dualidade do fenômeno vocal COMO TAL e do fenômeno vocal COMO SIGNO - do fato físico (objetivo) e do fato físico-mental (subjetivo), de maneira alguma do fato "físico" do som por oposição ao fato 'mental' da significação.

Há um primeiro domínio, interior, psíquico, onde existe o signo assim como a significação, um indissoluvelmente ligado ao outro; há um segundo, exterior, onde existe apenas o 'signo' mas, nesse momento, o signo se reduz a uma sucessão de ondas sonoras que merece de nós apenas o nome de figura vocal (SAUSSURE, 2004, p. 24)

Deve ser dada a devida atenção à riqueza complementar que esse parágrafo dos manuscritos oferece às linhas do CLG. Uma série de conceitoschave pode ser reformulada a partir dele, e penso ser nosso dever fazê-lo.

Em primeiro lugar, deve-se compreender que "signo" e "significante" são termos sinônimos no ELG. Além de o último estar claramente substituindo o primeiro no decorrer dos manuscritos, tal interpretação também encontra apoio em pelo menos duas passagens do próprio CLG, onde se lê que os conceitos "se acham associados às representações dos signos linguísticos ou imagens acústicas que servem para exprimi-los [os conceitos]" (SAUSSURE, 1995, p. 19, grifos meus) e que "chamamos signo a combinação do conceito e da imagem acústica: mas, no uso corrente, esse termo designa geralmente a imagem acústica apenas" (SAUSSURE, 1995, p. 81, grifo do autor). Essa ressalva é importante porque oferece uma hipótese para a utilização das aspas ao designar o que está em jogo no domínio exterior da linguagem, isto é, o "signo" como figura vocal. Se tomarmos a significação, nesse caso, como sinônimo de significado e signo como sinônimo de significante, sendo um a contraparte do outro, saberemos que não é possível conceber signo sem significação.

Em segundo lugar, é preciso não levar às últimas consequências a hipótese de que Saussure exclui o sujeito falante da teoria linguística. É certo que os dados disponíveis até a descoberta dos manuscritos não fazem menção direta ao sujeito, mas não podemos esquecer que Saussure não é o autor das palavras contidas no CLG ainda que lhe seja atribuída a obra. Não se trata de levar a julgamento os colegas que se empenharam na tentativa de reconstituir o pensamento do mestre; o trabalho era necessário, e a ciência deve reconhecer-lhes o mérito. A linguística moderna não seria possível sem ele; entretanto, não se deve reduzir a linguística saussuriana ao CLG. Por exemplo, que Saussure teria destacado o falante do famoso curso ministrado em Genebra entre 1906 e 1911 não é algo que se possa afirmar com base apenas na leitura do CLG, pois, como se sabe, a obra é uma coletânea das anotações de seus alunos e de poucos manuscritos cedidos pela sua família após a sua morte, os quais passaram por um notável trabalho de edição por parte dos organizadores do livro. Para esclarecer a discussão sobre a exclusão do falante da teoria saussuriana, é preciso recorrer aos manuscritos originais. Uma leitura atenta desses documentos, entretanto, não sustenta o falante como uma ausência na linguística que Saussure pensou.

Tal hipótese encontra apoio, principalmente, nas seguintes passagens dos manuscritos: "a primeira expressão da realidade seria dizer que a língua (ou seja, o sujeito falante) não percebe nem a ideia [...] nem a forma 
[...], mas apenas a relação" (SAUSSURE, 2004, p. 39) entre uma coisa e outra, a qual é "transportada pelo pensamento na consciência do sujeito falante", de modo que "só EXISTE linguisticamente o que é percebido pela consciência" (SAUSSURE, 2004, p. 44). Dizer que a realidade linguística depende da consciência do sujeito falante é o mesmo que dizer que a língua só existe na consciência dos falantes. De acordo com Saussure, a língua é um "tesouro depositado pela prática da fala em todos os indivíduos pertencentes à mesma comunidade" (1995, p. 21). Como se poderia imaginar conceber uma ciência da língua e ao mesmo tempo negligenciar seu depositante? Sem o falante, não é possível conceber sequer o signo, o qual é constituído de um "fato físico" e de um "fato físico-mental" - a face subjetiva da língua.

Em terceiro lugar, para acessar a complexidade do problema da linguagem, faz-se necessário ao menos atenuar a marca estruturalista imposta a Saussure. Conforme já explicitado, o CLG não propôs uma dicotomia entre língua e fala, da mesma maneira que o parágrafo anteriormente citado deixa claro que Saussure não propôs uma dicotomia entre a significação e o som; ao contrário, os dois termos estão em absoluta relação no sistema linguístico, assim como língua e fala estão em absoluta relação no interior da linguagem. A dupla essência da linguagem da qual Saussure trata nos manuscritos diz respeito às duas formas de se conceber o fônico: primeiramente, como figura vocal, isto é, destituído de todo sentido, e, finalmente, como signo, isto é, revestido de significação. Por sua vez, as duas formas de conceber o fônico demarcam os dois planos da linguagem, o plano individual, isto é, a fala - "o fenômeno vocal como tal" - e o plano social, isto é, a língua - "o fenômeno vocal como signo".

Desse modo, a fala é, para Saussure, o objeto de uma outra linguística, à medida que é exterior à língua, cujo lugar metodológico é dado por aquilo que Saussure (2004, p. 43) entende por fonética: o “domínio linguístico do som puro ou daquilo que serve de signo considerado em si mesmo e fora de qualquer relação com o pensamento". Logo, no plano da fala, tomada na concepção saussuriana que este texto se embasa, só se concebe uma sucessão de ondas sonoras que, para o linguista, nada significam além da sua diferença na cadeia falada, interessando, de fato, à análise do foneticista. Tem-se, então, dois domínios: o objeto da fonética, de um lado, e o objeto central da linguística, de outro, o qual representa, nas palavras de Saussure (2004, p. 43, grifos do autor): o "domínio linguístico do signo vocal (Semiologia)", que compreende, simultaneamente, o domínio "do pensamento relativo, da figura vocal relativa e da relação entre os dois".

Disso resulta a "distinção fundamental e única, em linguística", a qual "depende, então, de saber: se é considerado um signo ou uma figura vocal como signo (Semiologia = morfologia, gramática, sintaxe, sinonímia, retórica, estilística, lexicologia, etc. [...])", ou, "se é considerado um signo ou uma figura vocal como figura vocal (fonética)" (SAUSSURE, 2004, p. 44, grifos do autor). Nesse ponto, o próprio CLG revela o dualismo: "A linguística trabalha, pois, no terreno limítrofe onde os elementos das duas ordens se combinam" - isto é, elementos de ordem física combinados a elementos de ordem psíquico-física - "essa combinação produz uma forma e não uma substância" (SAUSSURE, 1995, p. 131, grifos do autor).

Finalmente, é a noção mesma de forma que introduz na linguística saussuriana o som enquanto signo, isto é, significante. Chama-se forma uma figura vocal que existe linguisticamente, ou seja, que o falante reconhece como um som da língua. Na condição de significante, a forma é uma figura vocal que tem a propriedade de significar algo para o falante. Isso quer dizer, conforme Saussure (2004, p. 37), que a forma "não tem, necessariamente, um 'sentido' preciso; mas ela é percebida como alguma coisa que é". Por essa razão, não há um meio de definir a forma em relação à figura vocal, uma vez que esta nada pode dizer sobre a língua; para defini-la, explica Saussure 
(2004, p, 38), é necessário "partir do dado semiológico" - isto é, a noção de forma, cara para a concepção saussuriana de língua, deve ser definida em relação ao som como signo. É disso que tratarei a seguir.

\section{A figura vocal como signo}

O falante, ao enunciar, produz uma porção sonora que se configura como uma massa amorfa de som; nesse momento, a condição do som que está em jogo é aquela que Saussure (cf. supra) considera o segundo domínio do dualismo da linguagem, no qual, como vimos, "existe apenas o 'signo', mas, nesse momento, o signo se reduz a uma sucessão de ondas sonoras que merece de nós apenas o nome de figura vocal". Em outras palavras, uma massa amorfa de som não é signo. Esse depende do recorte fonético, ou seja, é necessário dar forma à significação para concebê-la.

Por meio da descrição do dualismo da linguagem, Saussure (2004, p. 41-42, grifos do autor) esclarece o "extremo mal-entendido que domina as reflexões sobre a linguagem", o qual supõe "que existem termos duplos que comportam uma forma [...] - e uma significação", quando o correto seria dizer "que a forma é a mesma coisa que a significação, e que esse ser é quádruplo" de maneira que a "visão habitual" A/B = Significação/Forma deve ser substituída por $\mathrm{A} / \mathrm{B}$ = "diferença geral das significações" relativa à "diferença geral das formas"; "Uma significação" relativa a "Uma forma"/ Figura vocal. Em outras palavras, $A$ comporta, de uma só vez, o que Simon Bouquet (2009, p. 171) chamou de "arbitrário interno do signo" relação entre uma forma e uma significação - e "arbitrário sistêmico do signo" - relação entre a diferença geral das formas e a diferença geral das significações, enquanto $B$ é a figura vocal necessária que serve de forma em $A$. Por conseguinte, os dois modos de arbitrariedade do signo propostos por Bouquet lhe seriam, na verdade, ambos internos.
Isso significa dizer que o signo depende da forma na mesma medida em que a forma depende da figura vocal, que é o seu estado primeiro. Nas palavras de Saussure (2004, p. 38): "uma figura vocal se torna uma forma a partir do instante crucial em que é introduzida no jogo de signos que se chama língua". Dessa maneira, tem-se mais uma vez clara a relevância do sujeito falante para a linguística saussuriana, uma vez que a determinação da forma, a qual ensina a própria definição de língua, só é possível pela consciência do falante. É o falante quem introduz a forma no sistema linguístico através do recorte que faz da figura vocal, ou seja, é o falante quem define o signo e estabelece os sons da língua, uma vez que a "a língua só tem consciência do som como signo" (SAUSSURE, 2004, p. 157).

Mas como se dá o recorte da unidade que precipita o signo linguístico?

De acordo com Saussure (cf. 2004, p. 31), são duas as condições necessárias para que uma figura vocal se configure como forma: ela não pode ser isolada da relação de oposição que estabelece com outras formas no sistema, na mesma medida em que não pode ser isolada de seu sentido. Isso posto, tem-se imediatamente o fato primordial que gera toda a linguística saussuriana, isto é, o fato negativo. O que define uma forma é a "diferença geral das figuras vocais associada à diferença geral dos sentidos que se pode atribuir a elas" (SAUSSURE, 2004, p. 31, grifos do autor) - a língua é este jogo de valores morfológicos que não correspondem nem aos sentidos e nem às formas, mas a diferença que se estabelece entre os termos de mesma ordem. "Quem diz forma diz diferença com outras formas e nada mais” (SAUSSURE, 2004, p. 47, grifos do autor) à medida que o valor de um termo "resulta tão somente da presença simultânea de outros" (SAUSSURE, 1995, p. 133). Se tomamos a palavra como signo, não importa mais o som produzido para enunciá-la, interessa-nos apenas as diferenças fônicas que permitem distingui-la das demais, pois são essas diferenças que delimitam a significação. 
A essência do significante linguístico não é, então, constituída por um som e por uma ideia, mas pelas diferenças que isolam sua imagem acústica das demais. A imagem acústica, nesse sentido, não é o som em matéria, que é apenas físico, mas “a impressão (empreinte) psíquica desse som” (SAUSSURE, 1995, p. 80) - sendo uma entidade psíquico-física, o significante é ao mesmo tempo material e imaterial.

Isso significa que o som serve à ciência da língua no instante mesmo em que não pode mais ser considerado como tal, mas como signo. A unidade linguística não deve possuir, assim, nada de estreitamente fônico em seu caráter para assumir sua condição. Isso porque o som que serve de signo não é jamais separado da significação; em termos de língua, só acessamos o som se tomamos o todo que ele representa. De acordo com Saussure (1995, p. 120, grifos do autor):

Em resumo, a língua não se apresenta como um conjunto de signos delimitados de antemão, dos quais bastasse estudar as significações e a disposição; é uma massa indistinta na qual só a atenção e o hábito nos podem fazer encontrar os elementos particulares. A unidade não tem nenhum caráter fônico especial e a única definição que dela se pode dar é a seguinte: uma porção de sonoridade que, com exclusão do que precede e do que segue na cadeia falada, é significante de um certo conceito.

Conforme explicitado, a língua é então essa massa sonora indistinta cujos elementos, uma vez delimitados pelo sujeito falante, recalcam sua natureza puramente fônica numa forma psíquico-física, cuja relação de oposição e diferença com outros termos de mesma ordem estabelece o sistema linguístico. Uma unidade linguística é, antes de qualquer coisa, uma "porção de sonoridade" que, "com exclusão do que precede e do que segue na cadeia falada" - isto é, recortada pelo sujeito falante -, torna-se imediatamente significante, própria de significação.
Por conseguinte, o aspecto fônico é importante para a linguística tal como elaborada por Saussure, como uma ciência da língua, e não do discurso. Entretanto, o som que interessa para o estudo da língua não é o som como concretude, mas como abstração. Isso porque o exame linguístico proposto por Saussure sonega a realização; não importa o fenômeno vocal enquanto tal, uma vez que a pista fônica por si só não garante a abstração. Ao recorte da unidade são necessárias as diferenças fônicas que o sistema estabelece entre uma significação e outra e entre uma imagem acústica e outra. Portanto, o registro do som é importante para a análise linguística à medida que configura um traço distintivo, o qual só é possível na constituição da forma que precipita o som como signo, isto é, o som que é língua.

Em última análise, as reflexões apresentadas até aqui mostram o conceito de semiologia de tal maneira relacionado aos fatos linguísticos que a ciência dos signos parece se confundir com a própria noção de linguística. Isso porque Saussure (2004, p. 249) fala de uma semiologia cujo objeto central é o signo social uma vez que o fenômeno semiológico jamais "deixa fora de si mesmo o elemento da coletividade" - característica que, por sua vez, define a língua nos fatos de linguagem. A fala, com efeito, por não carregar unidades de significação, mas apenas massas amorfas, e, por constituir a parte individual da linguagem, não se adequa ao exame linguístico e tampouco semiológico.

Essas últimas considerações fazem surtir a questão: terá Saussure se precipitado ao afirmar que a linguística não é senão uma parte dessa ciência geral que é a semiologia, quando, de forma mais exata, a ciência dos signos não parece constituir outra coisa que não a expressão máxima da Linguística da Língua em oposição à Linguística da Fala? As evidências que assim nos permitem interrogar não cessam no exposto até aqui. Como dito, Saussure de fato sugere para língua e fala uma divisão metodológica, instaurando duas disciplinas distintas, onde é proposto "conservar o nome de Linguística para cada uma dessas duas disciplinas e falar duma Linguística da fala", 
porém, é "necessário não confundi-la com a Linguística propriamente dita, aquela cujo único objeto é a língua" (SAUSSURE, 1995, p. 28). Além disso, é no mínimo curioso que a escolha dos editores tenha sido posicionar tal proposta em capítulo subsequente àquele em que são elaborados os princípios da Semiologia. No manuscrito Sobre a essência dupla da linguagem, Saussure (2004, p. 65) defende que a diferença das unidades é o "princípio fundamental da semiologia, ou da 'língua', considerada regularmente como língua e não como resultado de estados precedentes". Compreende-se que o estudo sincrônico da língua não é só objeto da semiologia, mas o que a determina; ora, é a mesma relação que Saussure reconhece entre a língua e a linguística.

Não convém sugerir que não possa haver outros sistemas semiológicos além daquele que a língua constitui, visto os tantos desdobramentos da semiologia pensada por Saussure observados em tudo aquilo o que foi chamado de semiótica ao longo do século XX (cf. HÉNAULT, 2006). A atenção que chamamos é para o fato de que a semiologia que Saussure (2004, p. 100) propõe é uma “semiologia linguística", para não dizer uma linguística propriamente dita, de tal maneira que "se quiser fazer semiologia, você será obrigado [...] a constituir suas primeiras unidades" (SAUSSURE, 2004, p. 88) - tarefa que Saussure atribui, de fato, aos linguistas e que reflete o princípio primeiro da linguística: "é o ponto de vista que cria o objeto" (SAUSSURE, 1995, p. 15).

\section{Considerações finais}

O aspecto fônico da língua é o que cede à linguagem humana uma dimensão física e outra psíquico-física; mais do que isso, cada uma das partes da linguagem deve algo ao som. A parte exterior que remete à fisiologia da fonação em nada contribuiria à língua se o aparelho vocal não orquestrasse porções de sonoridade passíveis de recorte; a parte interior, por sua vez, nenhuma significação pode constituir antes do recorte fonético que serve de signo graças à relação de diferença que estabelece com outros termos de mesma natureza. Como explicitado, o fônico diz algo sobre o signo, e o signo diz tudo sobre a língua.

Isso porque o signo é uma figura vocal que foi delimitada na consciência do falante de modo a constituir uma forma reconhecida pela língua como algo que significa. Desse modo, uma forma não se define nem pelo som, nem pela significação, e nem pela relação de um certo som com uma certa significação - o valor da forma é sua diferença com outras formas. De acordo com Saussure (2004, p. 47), o falante - ou o linguista - não percebe "nem a forma, nem o sentido, nem, em terceiro lugar, a união indissolúvel da forma e do sentido, nem $4^{\circ}$ a diferença dos sentidos, mas $5^{\circ}$ a diferença das formas".

À medida que incide sob a consciência do falante a delimitação das formas e que esta se dá na associação imediata a uma significação, parece razoável admitir que o sentido marca o lugar do sujeito na linguagem. Isso significa que a impressão acústica do som como signo não indica um sentido preciso, mas efeitos de sentido. Assim, acredita-se que a constituição do falante não se dá na integração forma-sentido, mas antes na possibilidade de integração. É a propriedade significante da forma que marca a entrada do falante na língua, e não aquilo que ela significa. Essa hipótese sugere, por fim, rastros da questão do sentido no entorno da teoria linguística de Saussure.

\section{Referências}

BOUQUET, Simon. De um Pseudo-Saussure aos Textos Saussurianos Originais. Letras \& Letras, Uberlândia, v. 25, n. 1, p. 161-175, 2009.

HÉNAULT, Anne. História concisa da semiótica. Trad. Marcos Marcionilo. São Paulo: Parábola Editorial, 2006. 
SAUSSURE, Ferdinand de. Curso de Linguística Geral. Trad. Antônio Chelini, José Paulo Paes e Izidoro Blikstein. São Paulo: Cultrix, 1995.

SAUSSURE, Ferdinand de. Escritos de linguística geral. Trad. Carlos Augusto Leuba Salum e Ana Lucia Franco. São Paulo: Cultrix, 2004.

Recebido em $21 / 10 / 2015$

Aceito em 20/02/2016. 